EMBRYARIDDLE
Aeronautical University

SCHOLARLY COMMONS
International Journal of Aviation, Aeronautics, and Aerospace

\title{
Aviation Safety Regulations versus CNS/ATM Systems and Functionalities
}

Adeyinka Olumuyiwa Osunwusi

National Open University of Nigeria, aosunwusi@yahoo.com

Follow this and additional works at: https://commons.erau.edu/ijaaa

Part of the Aviation Commons

\section{Scholarly Commons Citation}

Osunwusi, A. O. (2020). Aviation Safety Regulations versus CNS/ATM Systems and Functionalities. International Journal of Aviation, Aeronautics, and Aerospace, 7(1). https://doi.org/10.15394/ ijaaa.2020.1448

This Literature Review is brought to you for free and open access by the Journals at Scholarly Commons. It has been accepted for inclusion in International Journal of Aviation, Aeronautics, and Aerospace by an authorized administrator of Scholarly Commons. For more information, please contact commons@erau.edu. 
The safety, security, efficiency, regularity, and sustainable development of international civil aviation operations revolve around, and are, therefore, mediated, administered, and regulated by a number of well-defined legal, policy, regulatory and methodological frameworks. These frameworks prescribe, inter alia, mandatory, advisory, prescriptive, or discretionary requirements in respect of interactivities in the civil aviation milieu.

Fundamentally, in relation to this structured web of legal, policy, regulatory, and methodological frameworks, the Convention on International Civil Aviation (otherwise known as the Chicago Convention, 1944), which entered into force on 4 April 1947, clearly represents the locus classicus. This convention established the International Civil Aviation Organization (ICAO) and is in accordance with Articles 91(b) and 92(b) of the Convention. With an authentic text that incorporates 96 Articles, the Chicago Convention essentially governs the activities of ICAO Contracting States, which are effectively States that have deposited either instruments of ratification or notification of adherence in respect of the Convention to the depositary - the Government of the United States of America.

The Chicago Convention embodies Annexes which have the status of international Standards and Recommended Practices (SARPs). Standards are specifications "for physical characteristics, configuration, material, performance, personnel or procedure, the uniform application of which is recognized as necessary for the safety or regularity of international air navigation and to which Contracting States will conform in accordance with the Convention" (ICAO, 2011, p. viii) while Recommended Practices are specifications "for physical characteristics, configuration, material, performance, personnel or procedure, the uniform application of which is recognized as desirable in the interest of safety, regularity or efficiency of international air navigation, and to which Contracting States will endeavor to conform in accordance with the Convention" (ICAO, 2011, p. viii). The ICAO's SARPs have been identified as having made an important contribution to "enhancing global aviation safety, interoperability, harmonization and efficiency" (ICAO, 2007a, para. 1.2). Today, there are a total of five Procedures for Air Navigation (PANS) and 19 Annexes, up from 18 following the addition of Annex 19 on Safety Management. There are also over 12,000 SARPs across the 19 Annexes and 5 PANS to the Chicago Convention (ICAO, 2019).

PANS, strictly speaking, do not have the same status as SARPs because while SARPs are adopted by the ICAO Council in pursuance of Article 37 of the Chicago Convention and subject to the full procedure of Article 90 of the Convention, the Procedures for Air Navigation are approved by the Council and recommended to Contracting States for worldwide application (ICAO, 2015). Frankly speaking, a greater chunk of the legal, policy, regulatory, and methodological frameworks at the national, sub-regional, and regional levels are directly distilled from the Chicago Convention 1944 and its Annexes. The Civil 
Aviation Regulations of a State are, therefore, a domestication of the Annexes to the Chicago Convention 1944 and reflect the requirements for uniformity in standards, regulations, procedures, and organizational structures imposed by Article 37 of the Convention. Article 38 of the Convention, though, allows a State to - in the event of departures from international standards and procedures on the grounds of impracticability of compliance or the desire to adopt differing regulations or practices - file a notification to that effect with the International Civil Aviation Organization.

This situation essentially underscores the global dimensions of civil aviation operations and the global nature of the essential elements of the civil aviation system. Huang (2009) noted that the risks incurred by civil aviation are global in nature and that global risks essentially require global management and call for international concerted action. Global management and international concerted action in respect of civil aviation operations necessarily exert tremendous demands not only on the imperativeness of consistency in terms of level of safety throughout the world but also on the necessity of assuring and maintaining equal levels of implementation of international civil aviation standards. It is equally true, though, that, given a number of peculiarities and exigencies - including political, geographical, developmental, governance and socio-economic realities, and differences - there will always be challenges in terms of uniformity of implementation of standards. This notwithstanding, international civil aviation standards define thresholds below which international civil aviation operations must not slide.

To ensure the continuing safety, security, efficiency, regularity, and sustainable development of air navigation, a number of the Articles of the Chicago Convention (e.g. Articles 12, 21, 23, 25, 26, 28, 32, and 37) impose wide-ranging obligations and responsibilities on States. Article 12, for example, provides that each Contracting State undertakes: to adopt measures to insure that every aircraft flying over or maneuvering within its territory and every aircraft carrying its nationality mark, wherever such aircraft may be, shall comply with applicable rules and regulations; to maintain the uniformity of its regulations with those established from time to time under the Convention; and to ensure the prosecution of all persons violating applicable regulations.

Of particular significance to operational safety and security is Article 32, under which a State incurs a responsibility in the area of facilitating the issuance of certificates of competency and licenses or the validation of such certificates or licenses issued by other States. To say the least, Article 32 to the Chicago Convention is critically germane to ensuring and assuring not only the continuing safety and security of international civil aviation operations but also the efficiency, sustainability, regularity, and economic development of international air navigation. The Article simply demands from States a responsibility that essentially 
targets the identification of functions and jobs that are critical to operational safety and security as well as the appropriate training and licensing/certification of personnel performing the identified functions and jobs.

Specifically, a license authorizes the performance of defined activities or functions which should otherwise be prohibited given the potentially serious implications of such functions or activities being performed improperly. The overall objective, of course, is not only to provide a set of standards, practices, and operational procedures which must be adhered to by the personnel so certified but also to enthrone a virile mechanism for the confirmation of personnel competency and for holding the personnel responsible and accountable for any actions undertaken in the performance of their safety-critical duties, including any act of commission or omission.

This paper explores the concept and nature of aviation safety within the broader context of safety and safety regulation; examines the safety dimensions of CNS/ATM (communication, navigation, surveillance/air traffic management) systems and functionalities and identifies the critical elements of the air navigation safety web. In addition, it examines the main issues and challenges relating to air navigation safety, and presents an argument for globally-inclusive considerations in respect of a harmonized approach to the regulation of all the safety-critical elements of air navigation service, particularly the certification and/or licensing of CNS/ATM systems and functionalities.

\section{The Concept and Nature of Aviation Safety}

The term 'safety' has been subjected to a wide variety of definitions and conceptualizations with the implication that today there is, according to Fisher (2006), the absence of a formal, operational definition for the term. Fisher (p. 14) argues that the absence of an operational definition of safety and the resultant susceptibility of the term to wide, subjective interpretations have the potential of not only hindering "consistency in the delivery of regulatory programmes and quantitative performance measurement" but also resulting in "conflicting priorities and the consequent allocation of resources to lesser issues."

This scenario notwithstanding, extant conceptualizations and interpretations of the term reveal elements of consistency with operational realities in the civil aviation realm. Transport Canada Civil Aviation's (TCCA) working definition of safety projects the term "safety" as "the condition where risks are managed to acceptable levels" (Fisher, 2006, p. 14). Using a variation of the definition provided by Hollnagel (2008), Lofquist, Greve and Olsson (2011) simply describe safety as "a process that produces outcomes that are safe" (p. 532). Safety has also been defined as the state in which the risk of harm to persons or property is reduced to, and maintained at or below, an acceptable level through a continuing process of hazard identification and risk management (EUROCONTROL, 2006). 
Safety has been identified as an essential element for the existence of civil aviation (Mwikya \& Mulwa, 2018) and has always been the prime reflection in the conduct of all aviation activities (Bala et al, 2013) aside from having been proclaimed by the aviation industry as its primary objective (Billings, 1997).

Safety is aviation's first priority and is at the core of ICAO's Strategic Objectives, which also incorporate goals such as capacity and efficiency, security and facilitation, economic development, and environmental protection. This creates a multi-dimensional orientation that is a reflection of the increasing complexity and dynamic nature of the civil aviation industry.

Aviation has been appropriately conceptualized as "a large industry, a true system of systems" that must necessarily be managed as such (European Commission, 2018, p. 11). As Lofquist (2010, p. 6) has also rightly noted: "The civil aviation industry can be described as a complex system of overlapping sociotechnical systems embedded within a highly competitive business environment, where safety is a primary, but not the only, goal." For this reason, aviation safety requires a multidisciplinary approach involving the technical, economic, managerial, and legal perspectives (Huang, 2009) while the reliability of the infrastructure in use constitutes one of the key elements of the safety of any modern mode of transportation (Borener \& Guzhva, 2014).

Conceptualized within the framework of civil aviation operations, safety presents a two-pronged manifestation - from the perspective of operational safety and from the technical perspective, otherwise referred to as system safety. Maurino (2017) describes system safety as an engineering discipline whose objective is to ensure the safety of technical system by designing "safety" into the system during the system's development. Maurino claims that "the significant progress in technology accomplished by aviation between the 1960s and the 1980s was in no small degree due to the contribution of system safety" (p. 8). From a historical perspective, the author further highlights a four-step hierarchical precedence-based architecture of intervention - design to eliminate safety concerns, incorporate safety devices, provide warning devices, and develop procedures and training which emphasizes the exclusivity of improving technical systems and the implications of human error in the course of actual system operations.

Within the context of its characteristic dynamism and complexity, the aviation industry has always existed as an embodiment of a tremendous vitality, which, according to Jung et al (2018), is premised upon the existence of a wellestablished and global partnership. One of the key elements to maintaining the vitality of civil aviation is ensuring safe, secure, efficient and environmentally sustainable operation at the global, regional and national levels (Mwikya \& Mulwa, 2018).

To say the least, security, efficiency, regularity, and environmental sustainability are closely linked to the safety of civil aviation. For this reason, 16 
of the Chicago Convention's 19 Annexes deal with safety, including the Annexes that relate to the efficiency and security of air navigation. Also, four PANS deal with the issue of the safety and efficiency of air navigation.

There is, though, a clear distinction between aviation safety and aviation security. Oster, Strong and Zorn (2013, p. 161) explains the distinction thus:

Improving aviation security involves thwarting attempts by individuals to disrupt, damage, or destroy parts of the aviation system intentionally. Improving other aspects of aviation safety involves reducing the chances that unintentional mistakes or unexpected failures of parts of the system will reduce the safety of air travel.

Notwithstanding this distinction, the fact remains that safety includes security (Huang, 2009) and aviation security is an important part of aviation safety (Oster et al., 2013). According to Huang (2009, p. 5), "No matter how airworthy an aircraft is, and how competent its crew members are, air travel will not be safe if it is subject to terrorist attacks."

Aviation safety is essentially paradigmatic and multi-dimensional as its nature rests squarely with a wide variety of operational, technical, and regulatory exigencies. It has become the concern of the whole world and its importance is unanimously recognized (Huang, 2009) just as it is also seen as "central to ensuring that air transport continues to play a major role in driving sustainable economic and social development" (Jung et al, 2018, p. 1).

The nature of aviation safety is such that there is nothing like absolute safety or the complete elimination of risks, accidents, or incidents. This situation has been attributed to the nature of the aviation industry, which renders the total elimination of accidents or serious incidents unachievable (Bala et al., 2013). It has been observed that if aviation must be free from any dangers or risks, it will not even exist at all because flight is inherently a risky venture carried out in a hostile environment at great speed (Huang, 2009). The importance of this reality is actually the fact that the safety, security, and efficiency of aviation revolves around regulatory, administrative, and operational approaches that are not only systematic, proactive, multi-dimensional, and dynamic but also completely devoid of complacency. As the late Dr. Assad Kotaite, the then President of the Council of ICAO, had rightly reiterated in his opening address to the 2006 Directors General of Civil Aviation Conference on a Global Strategy for Aviation Safety (ICAO, 2006, sec. 7.1) "There is absolutely no room for complacency where safety is concerned, there never was and there never will be". 


\section{Aviation Safety: A Paradigm Shift}

There have been considerable improvements in aviation safety records and this situation can be attributed to a wide variety of operational, technical, and regulatory factors. Dehais et al. (2015) ascribe these improvements in safety records to the development of automation in aviation, while Oster, Strong and Zorn (2013) attribute the improvement in aviation safety to technological improvements in aircraft, avionics and engines, improvement in navigational aids and air traffic management, improvement in weather forecasting, and better understanding of weather phenomena such as downdrafts and wind shear.

Paradoxically, these improvements have the potential to metamorphose into a double-edged sword. Borener and Guzhva (2014) have argued, in relation to air traffic management (ATM) operations, that the technological advances that improve ATM efficiency and safety have a secondary impact in the form of what the authors referred to as "degraded modes from malfunctioning or inoperable systems" (p. 1753). With this perspective, the increasing betterment of the aviation safety records consequent upon technological evolution may well be considered to be more of a paradoxical phenomenon that requires a paradigm shift in safety approaches in order to continue to ensure the safety, efficiency, and security of air navigation.

Historically, aviation safety has been built upon the reactive analysis of past accidents as well as the introduction of corrective actions to prevent the reoccurrence of those events (Bala et al., 2014). This overture deploys the prescriptive approach to managing safety and is also based exclusively on strict compliance with regulatory requirements. It is premised upon an acceptance of the fact that "learning from safety occurrences is an essential component to improving aviation safety" (ICAO, 2007b, para. 1.1). It equally emphasizes a research focus on aviation safety, which has been riveted on "analyzing accidents, investigating their causes, and recommending corrective action" (Oster et al., 2013, p. 149).

Interestingly, however, the trend today is towards increasing emphasis on proactive and predictive systems to manage safety (Galotti, Rao, \& Maurino, 2006). This is being driven by contemporary realities, including the reality of "a rapidly expanding industry and limited resources at oversight authorities" (Galotti et al., 2006, p. 6) as well as "evolving aviation safety realities particularly the connection between organizational issues and safety and the complexities of human performance within operational contexts" (Osunwusi, 2014, pp. 6, 10). These realities are actually revealing the sheer inadequacy of this reactive and predominantly regulatory approach to improving aviation safety thus forcing a paradigm shift towards a systematic approach to aviation safety that integrates risk management, compliance-based safety strategies and performance-based safety approaches as well as emphasizes human factors and the organizational dimensions of safety. 
It has been argued that aviation safety goes beyond accident prevention from a technical point of view and extends to more profound political, strategic, and legal dimensions, including preventive, remedial, and punitive measures (Huang, 2009). For this reason, there has been a shift towards a more proactive approach, which, in the words of Oster et al. (2013, p. 149), "involves identifying emerging risk factors, characterizing these risks through modeling exposure and consequences, prioritizing this risk, and making recommendations with regard to necessary improvements."

This proactive approach conceptualizes aviation safety as a multidimensional and multi-sectorial paradigm and extends the horizon of aviation safety to capture the entire spectrum of aviation safety management, thus culminating in the concept of Safety Management, which, according to Thomas represents a collection of specific practices for organizational safety management that has "emerged as a conglomerate of safety-related activities that enabled an organization to discharge their responsibilities under the spectra of self-regulation" (2012, pp. 1-2). It aims, in the words of Maurino (2017, p. 11), "at turning safety and its management in socio-technical systems into a business function, along lines similar to those through which finance, legal, human resources, quality and any other business of the organization are managed as business functions." It emphasizes a systems approach on safety, while focusing, at an aviation organization, on safety of the operation and the types of hazards that can contribute to a catastrophic accident (Roelen \& Klompstra, 2012), with the overall goal of allowing the identification and management of flaws before accidents occur (Kaspers et al, n.d.). Lofquist (2010, pp. 5-6) describes this type of approach as one involving "interaction and involvement from the system operators and business leaders and managers responsible for both system performance and for safety outcomes prior to undesired events", whilst also requiring "a robust safety management system that is integrated into the overall strategic business objectives of an organization within an expanded industrial business context that can anticipate changes in an operative environment while balancing safety with economic goals."

The global civil aviation realm took a bold step towards proactive and systematic safety strategies with the adoption on February 2013 by the ICAO Council of Annex 19 - Safety Management - with an applicability date of November 2013. As aviation safety management is becoming a regulatory requirement rather than an industry best practice (Roelen \& Klompstra, 2012), ICAO has introduced - under a provision that took effect on 24 November 2006 - a new requirement for States to ensure:

- The establishment of Safety Management System (SMS) as well as an acceptable level of safety; and 
- The implementation of SMS by aviation organizations, specifically aircraft operators, aircraft maintenance organizations, air traffic service providers and certified aerodrome operators. (Osunwusi, 2014, p. 11)

Safety Management system (SMS) is defined as "the systematic management of all activities to secure an acceptable level of safety" (van der Geest et al., 2003, p. 33) or a planned, documented and verifiable method of managing hazards and associated risks (Bottomley, 1999, cited in Thomas, 2012), which effectively moves the primary mechanism for safety management from prescriptive regulation to organizational responsibility (Thomas, 2012).

Thomas (2012) identifies three transitional phases for safety management. Based on the transition of safety management from the fragile system of 1920 s to 1970s - typified by accident investigation and individualized risk management and the safe system of 1970 to mid-1990s - typified by incident investigation and technology/regulation to the modern Ultra-safe system of mid-1990s onwards, typified by business management approach to safety, Thomas (2012, p. 3) also defines SMS as the "third age of safety."

Two interesting paradigmatic perspectives on safety have emerged from the evolving proactive, predictive, and systematic approach to managing safety, particularly within the context of human factors and the organizational ramifications of safety. These perspectives relate to the emergence of the concepts of "Safety Intelligence" and "Safety Wisdom." Safety intelligence refers to the various sources of quantitative information - incident data and other safety information on precursor events - which an organization may use to identify and assess various threats, and to provide "reasonable predictions about likely accidents and measures to avoid them" (Makins et al., 2016, p. 3).

Safety Intelligence, as reiterated in ICAO (2013), not only "provides actionable information used to drive ICAO's safety strategy and programmes" but also "enables the organization to create a holistic understanding of safety issues by consolidating and benchmarking a number of safety performance indicators and providing guidance used to develop assistance for Member States, regional and subregional organizations" (p. 17). Safety wisdom, on its part, refers to "the judgment and decision-making of those in senior positions who must decide what to do to remain safe, and how they use quantitative and qualitative information to support those decisions" (Makins et al., 2016, p. 5). It, therefore, rests squarely upon the critical-thinking ability of those at the top of the organizational hierarchy as well as on the perceptions of those leaders in relation to the philosophies of aviation safety vis-à-vis organizational goals.

Another paradigmatic shift that has emerged from the safety management concept is the organizational principle of safety culture or just culture, a paradigm that the European Commission (2018) has referred to as an enduring safety mindset. 
Safety or just culture represents a principle that lays a strong emphasis on a nonpunitive approach to safety information through an enduring protection of not only the information but also those who file such information. It also emphasizes the safety significance of non-criminalization of incidents and accidents. To be sure, the presence of internal rules for Just Culture is already an important aspect of European aviation organizations in keeping with Article 16(11) of Regulation (EU) No. 376/2014.

\section{Safety Dimensions of CNS/ATM Systems and Functionalities}

Aviation accidents and incidents are not, to say the least, stand-alone occurrences. As succinctly posited in the 2009 final report of the Causal Model of Air Transport Safety project commissioned by the Netherlands' Ministry of Transport and Water Management,

Aviation accidents tend to result from a combination of many different causal factors (human errors, technical failures, environmental and management influences) in certain characteristic accident categories (loss of control, collision, fire etc.), whose causes and consequences differ according to the phase of flight in which they occur (taxi, take-off, en-route etc.). (Ale et al., 2009, p. 8)

In ECORYS' (2013) study, five accident categories are identified - based on the EUROCONTROL Accident Incident Model - where ATM may contribute significantly in terms of accident causation or prevention. The accident categories comprise: mid-air collision, CFIT (controlled flight into terrain), runway collision, taxiway collision, and wake turbulence accident. Interestingly, the air transport operational sphere is replete with the history of accidents or incidents that underscore the safety ramifications of CNS/ATM systems and functionalities in respect of some of the accident categories identified in the ECORYS' study or in relation to the phases of flight highlighted in Ale et al (2009).

An often cited event in connection with the safety dimensions of CNS/ATM technical operations is the fatal mid-air collision at an altitude of 34,890 feet on the night of July 1, 2002 involving Bashkirian Airlines Flight 2937, a Tupolev TU-154 passenger jet on a northern heading of $004^{\circ}$, and DHL Flight 611, a Boeing 757 cargo jet on a western heading of $274^{\circ}$, over Ueberlingen, Germany in airspace controlled by Switzerland's private air navigation service provider - Skyguide. The accident killed the two crew members of the Boeing 757 and all the 69 passengers and crew aboard the Tupolev TU-154, including 45 Russian school children who were on a school trip to Costa Dorada, Spain. Investigators identified a number of causative factors including: procedural ambiguities in respect of TCAS' use; and a number of technical and procedural shortcomings on the part of Skyguide.

The series of CNS/ATM - related events contributing to the Ueberlingen accident included a sectorisation work being carried out in the night from 1 to 2 
July, 2002, in order to re-arrange the Zurich area control sectors for which there were neither briefings regarding the technical and operational implications nor coordination with adjacent air traffic control (ATC) units; the maintenance work being carried out, consequent upon the sectorisation exercise, on the image processing system of the main radar, which resulted in the use of a fallback system with the consequence of delayed radar data and an increase of the separation minimum from 5 to $7 \mathrm{NM}$. Other issues included the switching off for maintenance of the ground-based optical collision warning system, which could have drawn the attention of the duty air traffic controller (ATCO) to the pending collision; the lack of information to the duty ATCO, who was handling two workstations at the time of the accident, in respect of the maintenance of the main radar and the optical collision warning system; the non-availability to the Skyguide ATCO at the time of the accident of direct phone connections with adjacent ATC units; and the lack of an automatic change-over of incoming calls to the bypass system.

One particular downside of the outcome of the Ueberlingen accident is that Peter Nielsen, the lone ATCO handling the airspace at the time of the accident, and not an ATSEP (air traffic safety electronics personnel), had to pay the supreme price when, on February 24, 2004, he was stabbed and killed by a Russian, Vitaly Kaloyev, who had lost his wife and two children in the accident.

Beyond the Ueberlingen accident, there are quite a number of accidents or incidents where investigations had initially targeted the functional integrity of CNS systems or where either on-board avionics working cooperatively with groundbased CNS/ATM systems or a component of the CNS system has been implicated. An example is Alitalia Flight AZ404, a DC 9 airliner, which crashed into the Stadlerberg Mountain, Weiach, Switzerland on 14 November 1990, as it approached Runway 14 of Zurich Airport, Switzerland on an international passenger flight that originated from Milan Linate Airport, Italy killing all 46 people on board. Investigation found multiple factors leading to CFIT (controlled flight into terrain) with the initial focus of investigators being on whether the ILS was sending the proper signal consequent upon the mysterious glide path shown on the Radar track. Aside from pilot error and GPWS (ground proximity warning system) failure caused by a short-circuit on the NAV receiver, investigation concluded that the pilot's Instrument Landing System (ILS) display provided incorrect values due to a faulty NAV receiver as the ADI/HSI had apparently captured the glide slope.

Less than a year before Ueberlingen, specifically on October 8, 2001, at Milano Linate Airport, Italy, a Scandinavian Airlines MD 87 jet, on a take-off, crashed into a private Cessna 525 aircraft, which had strayed onto the runway in dense fog, killing all 110 passengers and crew aboard the MD 87 and all 4 passengers and crew aboard the Cessna as well as 4 airport workers on the ground. The lack of an Advanced Surface Movement Guidance and Control System (A- 
SMGCS) radar at Linate prevented the ATCO from detecting the presence of the Cessna on taxiway R6 intersecting the runway. The deployment of the same type of surveillance system could have also helped to prevent aviation's deadliest disaster at Los Rodeos (now Tenerife-North Airport) on March 27, 1977, which recorded 583 fatalities.

There is also the case of Loftleider Icelandic Airways Flight LL001, a DC 8 airliner operated on behalf of Garuda Indonesia Airways, which crashed, on 15 November 1978, into a rubber and coconut plantation about 2 kilometres from the threshold of runway 22 of Colombo-Katunayake Airport, Sri Lanka while on a Radar vectored ILS approach, killing 183 out of the 262 people on board. Although the probable causes of the accident were crew's error, erroneous distance/altitude information provided by the Radar controller and the failure of approach lighting system, the Icelandic Directorate of Civil Aviation blamed the accident on inadequate maintenance of ILS facilities resulting in a downward bending of the glide path approximately 3.5 nautical miles from touchdown zone. The Icelandic authority also revealed that the ILS at Colombo-Katunayake Airport had not been calibrated for 11 months as against international calibration policy requiring ground checks and flight calibration to be carried out once in three months and once every six months respectively.

The reference to inadequate maintenance of ILS facilities as a causative factor in a fatal air accident is not only an unmistakable pointer to the safety criticality of CNS/ATM systems and functionalities but is also a clear wake-up call to the need for globally-inclusive and internationally harmonized and standardized procedures for assuring the competency and certification of personnel involved in the task of ensuring the adequate maintenance, operation, trouble shooting and calibration of safety-critical CNS/ATM systems. Underscoring the significance of this reality and having regard to the need "to safeguard against erosion of technical expertise", van der Geest et al. (2003, p. 123) have, through Recommendation 7-3 in the seminal report on Aviation Safety Management in Switzerland, re-echoed the need for the licensing and certification of air traffic safety electronics personnel (ATSEP) and ATC equipment. Aside from this, the ATSEPs have been identified as playing a crucial part in the ATM system such that "mistakes of the ATSEPs might lead to incorrect operation of systems, with a potential negative impact on safety" (ECORYS, 2013, p. 30).

Two air events - an incident with no fatality and an accident involving 229 fatalities - vividly depict the possible nexus between CNS/ATM-related inadequacies, confusion, and failures and the possibility of a CFIT accident. The incident involved an Air New Zealand Flight NZ60 - a Boeing 767 - on an autocoupled ILS approach to runway 08 at Faleolo International Airport, Apia, Western Samoa, which, on the night of 29 July 2000, carried out a missed approach from an altitude of about 400ft, some 6 miles short of the runway due to a suspected 
erroneous glideslope capture. The timely go-around executed by the pilot in command helped to avert a CFIT that could have claimed 176 lives. Investigations revealed that the NZ60 crew had knowledge of NOTAMs on the status of Faleolo, including the fact that the ILS Glideslope had no standby transmitter and the fact that the ILS Glideslope, VOR, and ILS/DME were unmonitored. Investigations also revealed that the ILS Glideslope was actually in the control (monitor) bypass mode and operating without standby transmitter. With this, the unserviceable transmitter was sending out invalid glideslope guidance information with the transmission of only the Carrier plus Side Bands (CSB) while the Side Bands only (SBO) signal was missing. The aircraft's on-board cockpit glide path and localizer indications, though, were perfectly normal. The NZ60 incident actually provoked a response from the Secretary General of ICAO through the issuance of State Letter AN 7/5-01/52 dated 11 May, 2001, on the general subject of incidents caused by operational use of ILS signals radiated during testing and maintenance procedures.

The air accident, which killed 229 passengers and crew, occurred on August 6, 1997, and involved Korean Air Flight 801 - a Boeing 747-300 - which crashed into a remote area on Nimitz Hill, some 3 nautical miles short of the runway while on approach to runway 6L of Antonio B. Won Pat International Airport in the U.S. territory of Guam. The CNS/ATM issues related to the event included: the fact that the airport's ILS Glideslope was unserviceable, while the captain believed it was in service; and the crew's confusion about the location of the DME such that while the captain believed that the system was sited at the airport, it was actually located at the NIMITZ VOR site located some 3.3 nautical miles from the airport.

Aside from the direct implication of CNS/ATM facility functional inadequacy or failure on the safety of air navigation, quite a number of studies has established positive correlations between CNS/ATM performance and/or service availability and the safety and efficiency of air traffic services. A 2014 study (Borener \& Guzhva, 2014), which probed the direct impact of communication and surveillance facility service outages on aviation safety in terms of traffic separation events, found that unscheduled service outages of ATM systems were associated with lost or reduced traffic separation events, albeit the likelihood of a separation event was not dependent upon the type of facility that experienced a service outage. The seminal study - conducted with a data sample comprising 222 communication and 116 surveillance unscheduled service outages - revealed that the reduced or lost traffic separations associated with ATM facility service outages can be considered precursors to hazardous loss of traffic separation events.

Beyond air accidents and incidents, the safety significance of CNS/ATM technical operation is underscored, to a greater extent, by the increasing complexities of air navigation services, the continuous and sustained growth of traffic volumes worldwide, and the huge financial implication of investments in air navigation systems (vis-à-vis the emergence of new business models and their 
implications on safety). There is also the continuous emergence of new technologies, which is driving a revolutionary paradigm shift towards modernization, harmonization, system interoperability and extensive networking. Of particular relevance to the emergence of new technologies is the emerging threats and risks of cyber security to civil aviation operations.

As a corollary, the ongoing rapid transformation of the roles, jobs, and functions of ATSEPs consequent upon the increasing complexity of CNS/ATM operational and technical environments as well as the exponential growths of technological innovations, particularly the increasing incursion of automation technology into the CNS/ATM techno-operational terrains also constitutes a clear pointer to the safety dimensions of CNS/ATM systems and functionalities. It has been argued that "the heterogeneity and complexity of existing and emerging automated CNS/ATM systems are re-defining not only the roles and tasks of ATSEP but also issues surrounding their competency, certification, and authorization" (Osunwusi, 2019, p. 13).

This dimension brings into focus the safety dimension of the human elements in civil aviation operations. The human element, according to Dumitru and Boscoianu (2015, sec. 1) "is the most flexible, adaptable and valuable part of the aeronautical environment, while being the most vulnerable." The vulnerabilities surrounding the human element actually represent the key element underscoring the safety significance of aviation operations. They also exert great demands in respect of the institutionalization of competency-based, certification-enabled, and globally-harmonized procedures and mechanisms for safely managing and mitigating the hazardous effects of these vulnerabilities.

\section{Elements of the Air Navigation Safety Web}

In managing safety and creating the margin of safety, aviation has always relied on overlapping and interacting systems (Oster et al., 2013) consequent upon the inherent dynamic and complex nature of the industry. The aviation system has been described as being not merely safe, but resilient (European Commission, 2018) while air traffic services have been conceptualized as team efforts that necessarily involve different groups working collaboratively to deliver a seamless service to the aircraft (ICAO, 2004). However, in terms of what actually constitute aviation safety, including operational flight safety, a holistic consideration and examination of these "overlapping and interacting systems" are important not only for a meaningful conceptualization of the paradigm of aviation safety but also for the effective and efficient management of safety.

In relation to the shortcomings attending investigations into air accidents and incidents in recent times, Lofquist (2010) identifies, as one problem for the civil aviation industry, the excessive focus upon incidents and accidents as extraordinary events, while Oster, Strong and Zorn (2013, p. 150) note rather 
frankly that by "focusing on the root cause of an accident, organizational and managerial conditions that contributed to the accident may be overlooked." It can also be argued, as a corollary, that by focusing attention on a restrictive set of functionalities to the exclusion of others that are clearly enmeshed in the same safety web, functionalities as well as technical, operational, and administrative elements that impact operational safety may be overlooked.

The implication of this argument is that aviation safety is effectively a multi-dimensional and multi-sectorial concept whose influence permeates every fabric of the aviation system. Within this perspective, this paper proposes, as illustrated in Figure 1, the safety-critical elements of the air navigation safety web, based on functions and jobs relevant to air navigation and ATM.

A function is defined in ECORYS' (ECORYS, 2013, pp. 15-16) study on safety-related and safety-critical functions and jobs in Air Traffic Management/Air Navigation Services (ATM/ANS) as "an activity performed either by humans or a system which transforms an input into an output on the basis of established procedures and objectives" while a job is "all activities, intellectual and physical, performed by a person undertaking his/her prescribed duties".

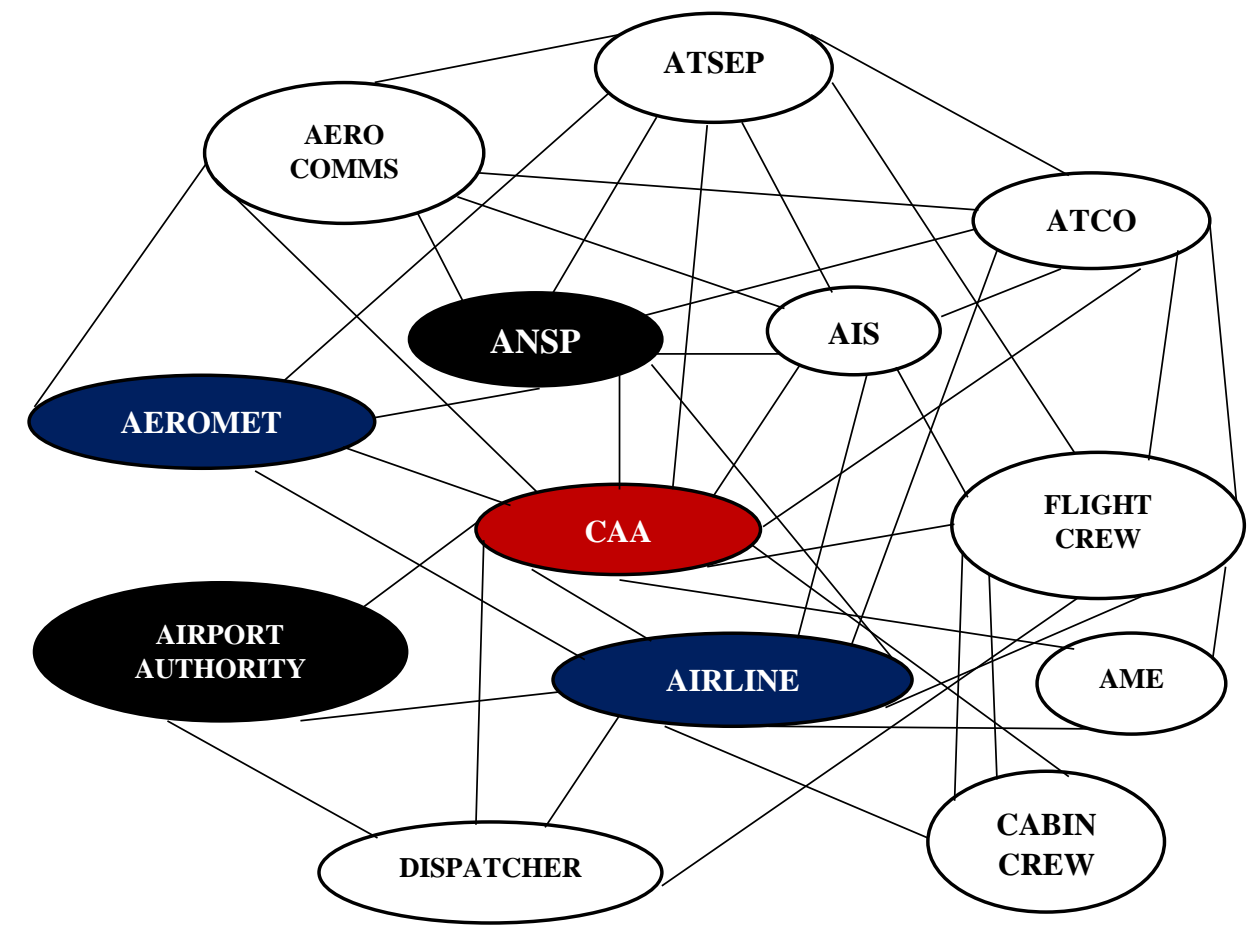

Figure 1: Air Navigation Safety Web. 
The study also identifies functions and jobs within the ATM/ANS services that are "safety-related" and "safety-critical;" a safety-related function being a function, the failure of which could impact safety and a safety-related job being a job that "involves performing at least one safety-related function" (p. 33) while "A function is safety-critical if a failure of the function could impact the safety and there are no barriers within the ATM/ANS system to prevent an accident following the of the function" (p. 33) and a job is safety-critical "if the job involves performing at least one safety-critical function" (p. 33).

Based on the definitions of safety-related and safety-critical functions and jobs and the application of the EUROCONTROL Accident Incident Model, which was originally christened the "Integrated Risk Picture (IRP) model", the ECORYS study identifies a total of 143 safety-related functions with the following 26 jobs regarded as safety-related: Air traffic controller, ATC supervisor, ATC instructor, ATC Assessor, ATC Examiner, ATSEP - System Monitoring and Control, ATSEP - Surveillance, ATSEP - Navigation, ATSEP - Communication, ATSEP - Data Processing, ATSEP - Instructor, Meteorological information officer, Aeronautical information service officer, Aerodrome Flight Information officer, Flight information service officer, Airspace Management Cell (AMC) coordinator, High level airspace policy makers, Network management officer, Flow Management Position (FMP), Airspace designers, Navigation data provision officer, ATM/ANS technical system designer, On-the-Job-Training-Instructor, HR Manager, Staff instructor, and safety management officer.

Of the 143 safety-related functions identified, 28 functions and 9 associated jobs are regarded as safety-critical. The safety-critical jobs are: Air traffic controller, ATSEP - System Monitoring and Control, ATSEP - Surveillance, ATSEP - Navigation, ATSEP - Communication, ATSEP - Data Processing, Aeronautical information service officer, Navigation data provision officer, and ATM/ANS technical system designer.

Aside from this, and having regard to the nature and safety significance of the jobs and functions of CNS/ATM technical personnel, the International Labour Organization (ILO) - in its International Standard Classification of Occupations and under ILO List of Professional Occupations No. 3155-ISCO 88 Minor Group (ILO, 2012, p. 75) - classifies ATSEPs as aviation professionals who occupy the same professional level as air traffic controllers, aircraft pilots and related associate professionals.

\section{Air Navigation Safety: Issues and Challenges}

The safety of air navigation revolves around a wide variety of factors emanating from both within and outside the aviation system. The Working Paper A36-WP/242, presented by the Kingdom of Saudi Arabia and Member States of the Arab Civil Aviation Commission (ACAC) to the 36th Session of the ICAO 
General Assembly in 2007, emphasize the fact that "Development and growth of air traffic at the international level require the adoption of modern methodologies, mechanisms and approaches in planning and implementing all elements relating to air navigation" (ICAO, 2007c, para. 4.1).

The expanding aviation system of today "comprises multiple and interrelated systems that are geopolitically diverse, technologically complex and highly multidisciplinary" (ICAO, 2013, p. 4). With this perspective, the question of whether the aviation industry will continue to be characterized by steady transformations is, perhaps, no longer open to debate. These transformations may not necessarily be limited to the future as they are actually becoming realities in the contemporary aviation realm. It is also clear that the transformational movement will continue to reveal issues and challenges that have far-reaching implications for the safety of civil aviation operations.

Smith, Roelen and den Hertog (2016, p. 3) note that transformations affecting the future of aviation system will come in the following two distinct categories:

- Progressive or rapid-onset physical, functional, and procedural changes that stakeholders plan for the aviation system with the deliberate intention of improving throughput, safety and/or efficiency/economics.

- Unintentional technological innovation, shifting operational tasks, subtle changes in organizations or actors in the system, and contextual factors external to aviation itself that can nonetheless influence the robustness of the support systems upon which operational safety depends.

The European Commission (2018) identifies five major challenges to safety in aviation. These are: 1) New Business Models ( the development of new business models due to the development of new technologies and increasing business competitiveness); 2) Automation (the increasing automation of aviation and the safety implications of automation failures); 3) Drones (the increasing presence of unmanned aircraft and challenges associated with safety and regulation); 4) Cybersecurity (the emerging threats of cyber-attacks); and 5) Adverse weather (the safety implications of weather-induced phenomena such as icing, thunderstorms, fog, micro bursts, and so on).

Oster et al (2013) identify the emerging issues and challenges in aviation safety as including: challenges relating to improving and maintaining the remarkable improvements in safety performance; issues surrounding the increasing development of larger and long-range aircraft and the concomitant demands in terms of reliability and performance; issues surrounding the extension of the safety record of large airlines to other less safe segments of commercial aviation; 
challenge relating to the increasing need to factor in safety risks from aviation infrastructure especially in respect of airport/runway operations and air navigation; issues surrounding the imperativeness of human factors in aviation safety; and challenges relating to the need to improve and extend data analytics.

In relation to the provision of air navigation services, the International Transport Workers' Federation (ITF) has identified challenges relating to corporatization, privatization, outsourcing, and subcontracting, which have "led to increasing fragmentation both in the provision of air traffic services and in the maintenance of navigational aids and ground-based equipment such as radar and telecommunications" (ICAO, 2004, sub-section 1.1.). There are also challenges related to environmental issues (including the problem of carbon emission), the increasing evolution of new technologies, and the emerging threats and risks of cyber security.

\section{CNS/ATM Functionalities: Certification Considerations}

One phenomenal dilemma of the global aviation safety realm is the undeniable fact that while the aviation system and aviation safety issues have steadily maintained their dynamic and multi-dimensional nature, the mechanisms for international standards, rules, and modus operandi from which national safety frameworks at institutional, regulatory, and legal levels draw their sustenance have remained, to a great extent, characteristically static, one-dimensional and bureaucratic. The existing regulatory frameworks for air navigation services and air traffic management on the global, regional and national levels are essentially disproportionate, disjointed, and incomprehensive.

Presently, there is a noticeable lack of any form of harmonized and globallyinclusive approach to system and personnel regulation as far as the provision of air navigation services, specifically CNS/ATM services, are concerned. This represents a fundamental safety gap particularly given the fact that such regulations have the potential of serving as a vehicle for fostering and ensuring the continuing safety, efficiency, and security of international air navigation. Kistan, Gardi and Sabatini note:

While there is a comprehensive regulatory framework for ATM (International Civil Aviation Organization (ICAO), European Aviation Safety Agency (EASA), FAA, Civil Aviation Safety Authority (CASA), etc.), today, ground-based ATM systems are not required to be formally certified in the same manner as avionics. For example, ATM systems are not required to comply with either the Radio Technical Commission for Aeronautics (RTCA) DO-278 or DO-254. (2018, p. 13)

Van der Geest et al. (2003) have also noted not only the fact that ATC equipment, unlike aeronautical equipment, is not certified but also the fact that ATC equipment technicians are not licensed contrary to almost all other personnel in 
aviation. While observing that Switzerland's Skyguide is not an exception, the authors posited that "it does nevertheless seem illogical that rulemaking around safety critical equipment and the associated personnel are so poorly developed" (van der Geest, 2003, p. 81). In the context of the European Union, this lack of a comprehensive regulatory framework for ground-based ATM systems extends, as revealed in the ECORYS' ( ECORYS, 2013, p. 11) study, to "other functions and jobs related to the design, production and maintenance of ATM/ANS systems and constituents as defined in Regulation (EC) No. 1108/2009."

As noted in the ECORYS' (2013) report, although the European Union's (EU) Commission Implementing Regulation (EU) No. 1035/2011 establishes safety provisions in respect of the engineering and technical personnel involved in the provision of CNS/ATM services, the regulation "neither provides any criterion for the definition of safety-related or safety-critical tasks performed by engineering and technical personnel, nor does it establish any requirement for its implementation" (ECORYS, 2013, p. 11). Aside from the noticeable absence of a comprehensive regulatory framework for CNS/ATM systems, the existing procedural and regulatory frameworks relating to the certification of CNS/ATM functionalities are equally disproportionate, and disjointed both at the global and regional levels. For instance, while there is a lack of a comprehensive licensing framework for air traffic safety electronics personnel (ATSEPs) in relation to the European Union, Commission Regulation (EU) No. 805/2011, which regulates air traffic controllers (ATCOs), contains specific requirements for the licensing of air traffic controllers, including persons and organisations involved therein, albeit there is a formalized designation for 'safety-related' and/or 'safety-critical' functions in relation to both ATSEPs and ATCOs (ECORYS, 2013, p. 11).

On the global perspective, despite the fact that there are international SARPs and a wide variety of guidance material regulating air traffic safety systems, there is no globally harmonized procedures for regulating the function of ATSEP nor is there any system of certification that will confer the responsibility that will mandate accountability. This scenario reflects the present unsafe status whereby air traffic controllers are essentially licensed, while there is no form of licensing or certification regime in respect of all the other safety-critical and security-sensitive personnel within the same air traffic management system.

Within this context, it is pertinent to state that Annex 1 to the Convention on International Civil Aviation currently provides Standards and Recommended Practices for the licensing of the following aviation personnel: flight crew members (pilots, flight engineers and flight navigators); air traffic controllers; aeronautical station operators; aircraft maintenance personnel (technicians/engineers/mechanics); and flight operations officers/flight dispatchers (ICAO, 2011, Chapter 1, section 1.2). However, there are currently growing agitations in respect of the need to expeditiously include certain critical functions 
hitherto excluded from Annex 1 given contemporary and emerging civil aviation operational realities, particularly the human factors and safety implications of the increasing incursion of the new technologies into civil aviation operation terrains. The International Transport Workers' Federation (ITF) has, for instance, argued for the introduction of a set of ICAO regulations that cover the licensing of all air navigation service providers including maintenance organizations and suppliers of safety-critical parts (ICAO, 2004).

Having regard to the peculiarities of their operational terrains, the identification of the safety-criticality of certain civil aviation functions, and the leeway copiously provided by Article 38 of the Chicago Convention 1944, some States - including Nigeria, which deposited a notification of adherence in respect of the Chicago Convention on 14 November 1960 - have entrenched in their national laws appropriate training, licensing and/or certification regimes for certain functions and personnel hitherto excluded from ICAO Annex 1. For example, Part 2 (Personnel Licensing) of the Nigeria Civil Aviation Regulations provides for the licensing of the following aviation personnel: flight crew members (pilots and flight engineers); flight dispatchers; flight instructors/ground instructors; aircraft maintenance engineers; aviation repair specialists; air traffic safety electronics personnel (ATSEP); parachute riggers; flight radio telephony operators (restricted licence); air traffic controllers; aeronautical station operators; and cabin crew (Nigerian Civil Aviation Authority, 2015, Part 2, Sub-section 2.2.1.1).

In spite of this kind of initiative by the States concerned, concerns still remain on the need to harmonize the licensing procedures and ensure the international uniformity requirements contained in Article 37 to the Convention on International Civil Aviation. In recent times, therefore, the agitations for the inclusion of certain aviation functions and jobs in ICAO Annex 1 - in order to meet Article 37 requirements - have been escalated to the ICAO General Assembly, which convenes every three years. Table 1 highlights some of the events and efforts that are especially relevant to the agitation for the inclusion of ATSEP in ICAO Annex 1 (Personnel Licensing) in recent times.

It is pertinent to observe, at this juncture, that reactions and responses at the ICAO General Assembly level to the deafening cries for the institutionalization of a globally harmonized and comprehensive certification and personnel regulation frameworks for the air navigation services realm have been somewhat mixed. At best, the situation reflects a lack of adequate comprehension of the philosophies of aviation safety particularly in the context of the growing complexity and modernization of civil aviation operations. For example, with respect to the joint working paper, A36-WP/210, presented to the 36th Session of the Assembly in 2007 by IFATSEA (International Federation of Air Traffic Safety Electronics Associations) and ITF, the ICAO Technical Commission, in view of the support of the majority of delegates for the proposal on licensing standards for ATSEP, 
"agreed that the concept of establishing licensing requirements for ATSEP could be supported in principle but had to be referred to the ICAO Council for further consideration in view of its financial implications" (ICAO Technical Commission, 2007, para. 30.4.5).

However, in respect of Working Paper A37-WP/160 on ATSEP competencies and licenses presented to the $37^{\text {th }}$ Session of the Assembly in 2010 by IFATSEA, the Commission reports:

Other comments shared were: in relation to A37-WP/160, that licensing was not the only means of demonstrating ATSEP competencies; that new provisions developed by the NGAP Task Force should not overly impact developing States and that transition measures be considered in the case of new requirements; and that the scope of the NGAP Task Force be expanded in a timely manner to include the development of competencies for aerodrome professionals. (ICAO Technical Commission, 2010, para. 45.8)

In consideration of Working Paper A38-WP/151 presented to the $38^{\text {th }}$ Session of the Assembly in 2013 by Indonesia, an ICAO Contracting State, the Commission comments:

The Commission recalled that ICAO had developed in cooperation with International Federation of Air Traffic Safety Electronics Associations (IFATSEA), competency frameworks for ATSEPs as a means to foster high quality and globally uniform training. The Commission did not come to consensus on whether a sufficient safety case was available to justify the development of international licensing provisions for personnel outside of the scope of the existing disciplines covered under Annex 1. (ICAO Technical Commission, 2013, para. 38.12) 
Table 1

Events Relevant to the Struggles for the Establishment of Universal ATSEP Certification Principles and Standards

\begin{tabular}{|c|c|}
\hline Year & Events \\
\hline 2000 & $\begin{array}{l}\text { 30 }^{\text {th }} \text { IFATSEA General Assembly, Montreal, Canada - Interactions among } \\
\text { IFATSEA members, the ICAO secretariat and ICAO Air Navigation Commission } \\
\text { members led to the recognition of the fact that ATSEPs were trained to certain } \\
\text { standards. }\end{array}$ \\
\hline 2003 & $\begin{array}{l}\text { ICAO 11 }{ }^{\text {th }} \text { Air Navigation Conference, Montreal, Canada, } 22 \text { September-3 October } \\
- \text { The conference, inter alia, highlighted the need to subject issues surrounding the } \\
\text { training, competency, and qualification of ATSEP to further investigation. }\end{array}$ \\
\hline 2004 & $\begin{array}{l}\text { Development of an ATSEP Training Manual, November - The Training Manual } \\
\text { was approved by the ICAO and the unedited version published as ICAO Doc } 7192- \\
\text { AN/857 (Part E-2). The Manual effectively set the stage for any proposal regarding } \\
\text { the inclusion of ATSEP in ICAO Annex } 1 \text {. }\end{array}$ \\
\hline 2004 & $\begin{array}{l}3^{\text {th }} \text { ICAO General Assembly, Montreal, Canada, } 28 \text { September }-8 \text { October }- \\
\text { Under Agenda Item 23: Consolidated statement of continuing ICAO policies and } \\
\text { practices related to communications, navigation, and surveillance/air traffic } \\
\text { management (CNS/ATM) systems, the International Transport Workers' Federation } \\
\text { (ITF) presented Working Paper A35-WP/198 on "Personnel Regulation as a Tool to } \\
\text { Support Safety and Security in Air Traffic Services", which invited the Assembly to, } \\
\text { inter alia, develop requirements for the certification or licensing of ATSEPs and } \\
\text { other safety or security sensitive or critical functions as well as request the ICAO } \\
\text { Secretariat to develop proposals for the regulation of working time for ATSEPs and } \\
\text { ATCOs. }\end{array}$ \\
\hline 2007 & $\begin{array}{l}\text { 36 }^{\text {th }} \text { ICAO General Assembly, Montreal, Canada, 18-28 September - Under } \\
\text { Agenda Item 30: Other Safety Matters, IFATSEA and ITF presented a joint working } \\
\text { paper, A36-WP/210. The working paper invited the ICAO General Assembly to, } \\
\text { inter alia, develop regulatory requirements for the licensing of ATSEPs and for the } \\
\text { certification of safety-critical CNS/ATM systems and equipment. }\end{array}$ \\
\hline 2010 & $\begin{array}{l}3^{\text {th }} \text { ICAO General Assembly, Montreal, Canada, } 28 \text { September - } 8 \text { October - } \\
\text { Under Agenda Item 45: Next Generation of Aviation Professionals, IFATSEA } \\
\text { presented working paper, A37-WP/160, on "Competencies and Licenses of Air } \\
\text { Traffic Safety Electronic Personnel (ATSEP)", which invited the Assembly to } \\
\text { recognize the global context of ATM/ANS, support the updating of ICAO regulations } \\
\text { including Annex 1, and endorse the concept of ATSEP licensing. }\end{array}$ \\
\hline 2013 & $\begin{array}{l}\text { 38 }^{\text {th }} \text { ICAO General Assembly, Montreal, Canada, } 24 \text { September - } 3 \text { October - } \\
\text { Under Agenda Item } 38 \text { : Other issues to be considered by the Technical Commission, } \\
\text { Indonesia presented working paper, A38-WP/151, on "The Integration of Air } \\
\text { Navigation Personnel into Annex 1", which invited the Assembly to request the } \\
\text { ICAO Council to update Annex } 1 \text { - Personnel Licensing - by developing } \\
\text { requirements for air navigation personnel, comprising AIS personnel, ATSEPs, and } \\
\text { flight procedure designer personnel. }\end{array}$ \\
\hline 2016 & $\begin{array}{l}3^{\text {th }} \text { ICAO General Assembly, Montreal, Canada, } 27 \text { September - } 7 \text { October - } \\
\text { Under Agenda Item 37, IFATSEA presented working paper, A39-WP/298, on "The } \\
\text { Inclusion of Air Traffic Safety Electronics Personnel into Annex 1", which invited } \\
\text { the Assembly to request the Council to undertake the necessary steps to develop } \\
\text { licensing requirements for ATSEP including updating ICAO Annex } 1 \text {. }\end{array}$ \\
\hline
\end{tabular}


The Commission comments further:

The Commission noted that the absence of international licensing provisions would not preclude States or regions from establishing their own national certification or licensing requirements. The Commission agreed that, resources permitting, the ICAO Council be requested to identify the safety case for the development of international licensing provisions beyond the current scope of disciplines covered under Annex 1. (ICAO Technical Commission, 2013, para. 38.12)

A literal interpretation of the ICAO Technical Commission's comments above would suggest not only a tacit admission of the safety significance and an endorsement of licensing provisions for ATSEPs but also a veiled dismissal of the need for international uniformity in the spirit of Article 37 to the Chicago Convention. The comments also suggest a situation where operational safety is held hostage by undue and unsafe considerations of the economic consequences of treading the paths of safety, security, and operational efficiency.

\section{Conclusion}

This paper explored issues surrounding aviation safety within the context of a globally-harmonized and comprehensive safety regulation environment and with an emphasis on the safety ramifications of CNS/ATM systems and functionalities. The dynamic and complex nature of aviation safety is quite incontestable and is tied to the evolutionary strides of the aviation systems. The larger picture that this assertion is painting is that functionalities, tasks, systems, and techniques that were considered safe or unsafe at a point in time in the past may not necessarily be the case today. As Huang (2009) has rightly argued:

Safety is also a dynamic rather than static concept. It has a strong temporal sense. What was considered safe or unsafe yesterday may not be so today. (p. 4)

The imperativeness of institutionalizing a unified and globally-inclusive approach to the regulation of CNS/ATM systems and personnel cannot be overemphasized. A unified approach to system certification has the potential of not only checking the chaotic deployment of a multiplicity of systems but also ensuring that CNS/ATM systems are designed, built, installed, and commissioned in accordance with the same globally-specified standards of safety, security, and reliability.

The benefits of a unified approach to regulating CNS/ATM personnel include: 
- Harmonized licensing and certification approaches that foster the standardization of competences and a uniform level of service as well as uniform and highest standards of operational safety;

- The efficiency, safety, and regularity of operations strengthened by harmonized and globally-standardized competency-based training and certification frameworks that emphasize responsibility and accountability;

- The consequential development and availability of well-defined globallyinclusive safety requirements for personnel involved in the maintenance, operation, installation, supervision, calibration, and commissioning of CNS/ATM systems. The safety requirements will also provide veritable means for confirming and certifying the competence of personnel;

- Harmonized environments for coordinating all air traffic management activities in furtherance of the safety, security, efficiency, and regularity of air navigation; and

- The harmonization of regulatory frameworks for air navigation services vis-à-vis the global civil aviation regulatory framework.

To be sure, automation is a naked reality of today's ATM operational environments. Although, the reality surrounding the "ironies" and "surprises" of automation has been sufficiently acknowledged and defined (e.g., Bainbridge, 1983; Dehais et al., 2015; Sarter, Woods \& Billings, 1997), CNS/ATM technical personnel continue to face challenges of novelties such that there is an overarching need for harmonized, standardized and well-defined competency-based training and regulatory frameworks that are tailored towards specific levels of automation. 


\section{References}

Ale, B., Bellamy, L. J., Cooke, R., Duyvis, M., Kurowicka, D., Lin, P. H., . . . Spouge, J. (2009). Causal model for air transport safety: Final report. Amsterdam: The Ministry of Transport and Water Management.

Bainbridge, L. (1983). Ironies of automation. Automatica, 19(6), 775-779. Retrieved from www.ise.ncsu.edu/wpcontent/uploads/2017/02/ Bainbridge_1983_Automatica.pdf/

Bala, I., Sharma, S. K., \& Kumar, S. (2013). Exploring raw safety aspects in aviation industry. Computer Engineering and Intelligent Systems, 4(1), 8097.

Bala, I., Sharma, S. K., Kumar, S., \& Shrivastava, R. (2014). Exploring safety aspects of aviation industry. Advances in Aerospace Science and Applications, 4(1), 37-44.

Billings, C. E. (1997). Aviation automation: The search for a human-centered approach. Mahwah, NJ: Lawrence Erlbaum.

Borener, S. S., \& Guzhva, V. S. (2014). Analysis of the effects of communication and surveillance facility service outages on traffic separations. Risk Analysis, 34(9), 1753-1762. doi:10.1111/risa.12192

Dehais, F., Peysakhovich, V., Scannella, S., Fongue, J., \& Gateau, T. (2015). "Automation surprise" in Aviation. In: Proceedings of the 33rd Annual ACM Conference on Human Factors in Computing Systems CHI 2015, 1823 April 2015, Republic of Korea. doi:10.1145/2702123.2702521

Dumitru, I. M., \& Boscoianu, M. (2015). Human factors contribution to aviation safety. International Conference of Scientific Paper AFASES 2015, Brasov, Romania, 28-30 May, 2015.

ECORYS. (2013). Study on safety-related and safety-critical functions and related jobs in ATM/ANS. Rotterdam: ECORYS.

EUROCONTROL. (2006). Implementation of ATM safety management systems remains a priority for Europe. ICAO Journal, 61(6), 20-25.

European Commission. (2018). Aviation safety - Challenges and ways forward for a safe future. http://dx.doi.org/10.2777/417337

Fisher, B. (2006). Business model focused on risk management enhances safety programme decision-making. ICAO Journal, 61(6), 14-16.

Galotti, V., Rao, A., \& Maurino, D. (2006). ICAO initiative promotes global approach to SMS implementation. ICAO Journal, 61(6), 6-39.

Huang, J. (2009). Aviation safety and ICAO. The Netherlands: Kluwer Law International.

ICAO. (2004). Personnel regulation as a tool to support safety and security in air traffic services. Technical Commission Working Paper A35-WP/198, 35th Session of the ICAO General Assembly. Retrieved from www.icao.int/ Meetings/AMC/MA/Assembly 35th Session/wp198_en.pdf 
ICAO. (2006). Report of the directors general of civil aviation conference on a global strategy for aviation safety, Doc 9866, DGCA/06, 20-22 March 2006, Montreal, Canada.

ICAO. (2007a). Agenda item 25: Follow-up of the DGCA/06 conference on a global strategy for aviation safety. Working Paper A36-WP/50, 36th Session of ICAO General Assembly, 25 July 2007. Retrieved from www.icao.int/Meetings/AMC/MA/Assembly $36^{\text {th }}$ Session/wp50_en.pdf

ICAO. (2007b). Agenda item 28: Protection of certain accident and incident records and of safety data collection and processing systems in order to improve aviation safety. Working Paper A36-WP/112, 36th Session of ICAO General Assembly, 29 September 2007.

ICAO. (2007c). Agenda item 32: Development of an up-to-date consolidated statement of continuing ICAO policies and practices related to a global ATM system and communications, navigation and surveillancelair traffic management (CNS/ATM) systems. Working Paper A36-WP/242, 36th Session of ICAO General Assembly, 18 September 2007.

ICAO. (2011). Annex 1 to the convention on international civil aviationpersonnel licensing (11th ed.). Montreal, Canada: Author.

ICAO. (2013). State of global aviation safety. Montreal, Canada: Author.

ICAO. (2015). Procedures for air navigation services - training (PANS-TRG), Doc 9868 (2nd ed.). Montreal, Canada: Author.

ICAO. (2019). How ICAO develops standards. Retrieved from www.icao.int/about-icao/AirNavigationCommission/Pages/how-icaodevelops-standards.aspx

ICAO Technical Commission. (2007). Report of the technical commission on agenda item 30. Working Paper A36-WP/359, 36th Session of ICAO General Assembly, 26 September 2007. Retrieved from www.icao.int/Meetings/AMC/MA/Assembly 36th Session/wp359_en.pdf

ICAO Technical Commission. (2010). Report of the technical commission on agenda items 38, 40, 41 and 45. Working Paper A37-WP/399, 37th Session of ICAO General Assembly, 5 October 2010. Retrieved from www.icao.int/Meetings/AMC/Assembly37/Working Papers by Number/wp399_en.pdf

ICAO Technical Commission. (2013). Report of the technical commission on agenda items 35, 36, 37 and 38. Working Paper A38-WP/413, 38th Session of ICAO General Assembly, 10 October 2013. Retrieved from www.icao.int/Meetings/a38/Documents/WP/wp413_en.pdf

ILO. (2012). International standard classification of occupations - ISCO-08, 1. Geneva: International Labour Organization.

Jung, H., Merens, M., Valipour, M., Liang, X., Abboud, D., Wen, H. A., . . . Zimmerman, R. (2018). Data-driven decision-making processes, data 
services and applications for global aviation safety. ITU Journal: ICT Discoveries, Special Issue No. 2, 16 Nov. 2018.

Kaspers, S., Karanikas, N., Roelen, A., Piric, S., \& de Boer, R. J. (n.d.). Review of existing aviation safety metrics. RAAK PRO Project - Measuring Safety in Aviation, Project S10931. Retrieved from www.amsterdamuas.com/ .../aviation/measuring-safety-in-aviation-project/review-existing- safetymetrics17.pdf/

Kistan, T., Gardi, A., \& Sabatini, R. (2018). Machine learning and cognitive ergonomics in air traffic management: Recent developments and considerations for certification. Aerospace 2018, 5, 103. http://dx.doi.org/10.3390/aerospace5040103

Lofquist, E. A. (2010). The art of measuring nothing: The paradox of measuring safety in a changing civil aviation industry using traditional safety metrics. Safety Science, 48(10), 1520-1529. http://dx.doi.org/10.1016/j.ssci.2010.05.006

Lofquist, E.A., Greve, A., \& Olsson, U.H. (2011). Modeling attitudes and perceptions as predictors for changing safety margins during organizational change. Safety Science, 49, 531-541. doi:10.1016/j.ssci.2010.11.007

Makins, N., Kirwan, B., Bettignies-Thiebaux, B., Bieder, C., Kennedy, R., Sujan, M-A., . . . Reader, T. (2016). Keeping the aviation industry safe - Safety intelligence and safety wisdom. A Future Sky Safety White Paper. doi:10.13140/RG.2.2.14656.53763

Maurino, D. (2017). Why SMS: An introduction and overview of safety management systems. ITF Discussion Paper 2017-16. Paris: International Transport Forum.

Mwikya, N. K., \& Mulwa, S.A. (2018). Implementation of aviation safety standards and performance of air transport industry: A conceptual perspective. African Journal of Business and Management, 4(2), 20-33.

Nigerian Civil Aviation Authority. (2015). Nigeria civil aviation regulations. Retrieved from http://www.ncaa.gov.ng/regulations/ncaa-regulations/

Oster, C. V., Strong, J. S., \& Zorn, C. K. (2013). Analyzing aviation safety: Problems, challenges, opportunities. Research in Transportation Economics, 43, 148-164.

Osunwusi, A. O. (2014). Safety management system: A systems approach to aviation safety. NAAEMAG (Official Journal of the National Association of Air Traffic Engineers), 4(03), 10-25.

Osunwusi, A. O. (2019). Aviation automation and CNS/ATM-related humantechnology interface: ATSEP competency considerations. International Journal of Aviation, Aeronautics, and Aerospace, 6(4). https://doi.org/10.15394/ijaaa.2019.1390 
Roelen, A. L. C., \& Klompstra, M. B. (2012). The challenges in defining aviation safety performance indicators, Preprint for PSAM 11 \& ESREL 2012, 2529 June2012, Helsinki, Finland. Retrieved from www.researchgate.net/ publication/267406066_The_Challenges_in_defining_aviation_safety_per formance_indicators

Sarter, N. B., Woods, D. D., \& Billings, C.E. (1997). Automation surprises. In G. Salvendy (Ed.), Handbook of human factors and ergonomics (2nd ed.). New York: Wiley.

Smith, B. E., Roelen, A. L. C., \& den Hertog, R. (2016). Aviation safety concerns for the future. Journal of Safety Studies, 2(2), 1-11.

Thomas, M. J. W. (2012). A systematic review of the effectiveness of safety management systems. Canberra, ACT: Australian Transport Safety Bureau.

van der Geest, P. J., Piers, M. A., de Jong, H. H., Finger, M., Slater, D. H., van Es, G. W. H., \& van der Nat, G. J. (2003). Aviation safety management in Switzerland: Recovering from the myth of perfection. Zurich and Amsterdam: Swiss Department of Environment, Traffic, Energy and Communication (DETEC) and National Aerospace Laboratory (NLR). 